\title{
Representações sociais do envelhecimento e do rejuvenescimento para mulheres que adotam práticas de rejuvenescimento
}

\author{
Amanda Castro \\ Larissa Antunes \\ Universidade Federal de Santa Catarina, SC, Brasil \\ Annie Mehes Maldonado Brito \\ Universidade Federal do Pampa, RS, Brasil \\ Brigido Vizeu Camargo \\ Universidade Federal de Santa Catarina, SC, Brasil
}

\begin{abstract}
Resumo
Esta pesquisa teve por objetivo compreender as representações sociais do envelhecimento e do rejuvenescimento para mulheres que adotam práticas de rejuvenescimento. Participaram 40 mulheres entre 30 e 60 anos, sendo que 20 utilizavam práticas não invasivas e 20 faziam uso de práticas invasivas e minimamente invasivas. Foi empregada entrevista semidiretiva e não estruturada para investigação das representações sociais do envelhecimento e do rejuvenescimento e questionário contendo questões de caracterização das participantes. A análise dos dados empregou estatística descritiva e relacional. Os resultados indicaram que as representações sociais do envelhecimento e do rejuvenescimento apresentam elementos distintos, de acordo com o tipo de prática adotada. A pressão social e a cobrança das mulheres surgem como elementos representacionais que justificam a adoção de práticas de rejuvenescimento. Por fim, o envelhecimento é apresentado como uma condição subjetiva.
\end{abstract}

Palavras-chave: Representações sociais; Envelhecimento; Rejuvenescimento.

\section{Social representations of aging and rejuvenation for women who adopt rejuvenation practices}

\begin{abstract}
This research aimed to investigate the social representations of aging and rejuvenation for women that adopt rejuvenation practices. The participants were 40 women aged from 30 to 60 years old. Half of them $(n=20)$ have used non-invasive rejuvenation practices while the other half $(n=20)$ have used invasive and/or minimal invasive rejuvenation practices. A semidirective and unstructured interview was used to investigate the social representations of aging and rejuvenation. Furthermore, a structured questionnaire was used and included objective questions related to participant's demographics. The data analysis involved descriptive and relational statistics. The results indicate that the social representations of aging and rejuvenation showed distinct elements, associated with each type of rejuvenation practice adopted. The elements such as social pressure and to be hard on yourself appears related to the type of rejuvenation practice adopted by the women. Lastly, the aging was meant as a subjective condition.
\end{abstract}

Keywords: Social Representation; Aging; Rejuvenation.

\section{Representaciones sociales del envejecimiento y del rejuvenecimiento para mujeres que adoptan prácticas de rejuvenecimiento}

Resumen

Esta investigación tuvo el objetivo de comprender las representaciones sociales del envejecimiento y del rejuvenecimiento para mujeres que adoptan prácticas de rejuvenecimiento. Participaron 40 mujeres entre 30 y 60 años, siendo que 20 de las mismas utilizaron prácticas no invasivas y otras 20 hicieron uso de prácticas invasivas y mínimamente invasivas. Se utilizó la entrevista semidirectiva y no estructurada para la investigación de las representaciones sociales del envejecimiento y del rejuvenecimiento, y un cuestionario conteniendo preguntas de caracterización de las participantes. Para el análisis de datos se empleó la estadística descriptiva y relacional. Los resultados indicaron que las representaciones sociales del envejecimiento y del rejuvenecimiento presentan elementos distintos, de acuerdo con el tipo de práctica adoptada. La presión social y la exigencia sobre las mujeres surgen como elementos representacionales que justifican la adopción de prácticas de rejuvenecimiento. Por fin, el envejecimiento es presentado como una condición subjetiva.

Palabras clave: Representaciones Sociales; Envejecimiento; Rejuvenecimiento. 


\section{Introdução}

No Brasil, vem ocorrendo o alargamento do topo da pirâmide etária em decorrência de um rápido processo de envelhecimento populacional que resulta principalmente do aumento da expectativa de vida e da redução da natalidade. O Relatório sobre a Situação da População Mundial (UNFPA, 2011) indica que dentre os sete bilhões de habitantes do mundo, 893 milhões são idosos. Os resultados da Pesquisa Nacional por Amostra de Domicílios (PNAD) do Instituto Brasileiro de Geografia e Estatística (IBGE, 2015) indicam significativo crescimento do segmento de pessoas de 60 anos ou mais de idade no país, sendo que a participação de pessoas na faixa dos 60 anos ou mais de idade em 2014 foi de 13,7\%, 0,7\% maior que em 2013. A região sul registrou o maior percentual de idosos, com $15,2 \%$, seguida pela região Sudeste, com $15,1 \%$. Os dados indicam ainda mudança na estrutura etária, com o alargamento do topo da pirâmide e estreitamento de sua base, demonstrando um envelhecimento da população. Devido a este fenômeno demográfico mundial de envelhecimento populacional, principalmente nos países em desenvolvimento, pesquisadores têm ampliado seu interesse em estudos sobre os aspectos psicossociais que envolvem este processo (Baltes, 1987; Camargo, Contarello, Wachelke, Morais \& Piccolo, 2014; Neri, 2013; Silva, Ogata, \& Oliveira, 2015; Torres, Camargo, Boulsfield \& Silva, 2015).

As características socioculturais e psicossociais são relevantes para o modelo de envelhecimento bem sucedido de Baltes e Baltes (1990). Tais aspectos são abordados a partir das contribuições da Teoria do Desenvolvimento ao longo da vida (lifespan), que concebe o ciclo vital como constituído de uma contínua progressão do desenvolvimento, desde o nascimento até a morte, e assume uma perspectiva ontogenética. $\mathrm{O}$ referido modelo parte da compreensão de que o desenvolvimento humano ocorre ao longo de toda a vida e no processo de envelhecimento existem perdas e ganhos que sofrem influência do contexto de inserção do indivíduo (Baltes, 1987; Neri, 2013).

As crenças e teorias leigas sobre o envelhecimento organizam e justificam práticas, as quais sustentam o entendimento da realidade e tem um importante efeito na vida das pessoas idosas. Assim, o envelhecimento pode se qualificar como um objeto social, presente em diversos contextos do cotidiano relacionados a este tema (Camargo et al., 2014; Wachelke \& Contarello, 2011). Moscovici (1961/2012) considera que as representações sociais compreendem um sistema de valores, noções e práticas que conferem aos indivíduos as formas de se orientarem no meio social. Assim, uma representação social sempre está simbolizando algo, constituindo-se em uma nova leitura, uma construção simbólica do objeto que representa (Jodelet, 1989).

Os estudos realizados por Veloz, NascimentoSchulze e Camargo (1999) foram precursores na investigação sobre representação social do envelhecimento. Esse estudo, desenvolvido por meio de entrevistas com idosos residentes na cidade de Florianópolis, destaca três representações sociais diferentes acerca do envelhecimento. A primeira como representação doméstica e feminina relativa à perda dos laços familiares, caracterizada pela saída dos filhos do núcleo familiar. A segunda, tipicamente masculina, em que o envelhecimento é caracterizado como perda do ritmo de trabalho, associado à aposentadoria. A terceira e a última representação, mais utilitarista, apresenta o envelhecimento como um desgaste natural relativo às perdas orgânicas.

No que concerne às perdas ocasionadas pelo envelhecimento, é possível destacar, de acordo com Papaléo Netto (2002), as rugas, cabelos brancos, declínio do tônus muscular, surgimento de doenças crônicas, diminuição da atividade e da potência sexual, saída do mercado de trabalho, saída do lar pelos filhos. Craciun e Flick (2014) enfatizam que uma pessoa é reconhecida socialmente como velha a partir dos sinais físicos visíveis (cabelos brancos, rugas e manchas) e da lentificação dos movimentos. A mídia propaga informações sobre rejuvenescimento, relacionando-o com bem-estar, atividade, beleza e jovialidade. Essa propagação fomenta a perspectiva de que o ideal seria viver muito e envelhecer pouco.

As pessoas buscam viver mais, no entanto, desejase evitar ou retardar o envelhecimento diminuindo as perdas decorrentes desse processo. O rejuvenescimento está relacionado com as perdas trazidas pelo envelhecimento, com a tentativa de atenuá-las. Mas ele se apresenta mais subjetivo e menos funcional, pois se vincula à aparência, ao sentir-se jovem. É possível considerar que as práticas de rejuvenescimento sejam relevantes no equilíbrio entre perdas e ganhos durante o envelhecimento quando concebidas pelo indivíduo como estratégias centrais dos comportamentos saudáveis durante todo o curso da vida (Teixeira et al., 2007). Ao longo das décadas, as representações sociais do rejuvenescimento foram difundidas, e o rejuvenescimento contemplava aspectos funcionais, associados à saúde e longevidade; aspectos sociais, ligados a mudanças do estilo de vida e maior liberdade para o exercício de diferentes papéis sociais; e o aspecto estético, relacionado à normatização do corpo em busca da beleza física (Castro, Aguiar, Berri, \& Camargo, 2016). 
Zani (1994) apresenta o rejuvenescimento como o resultado do uso de um bloco de métodos cirúrgicos, clínicos, ou baseados em terapias alternativas naturais, com o objetivo de diminuir a aparência envelhecida e obter um aspecto físico jovem. Apesar dos ideais de beleza corporal feminina sofrerem modificações ao longo do tempo, as mulheres mais do que os homens são incentivadas a mudar sua forma corporal em conformidade com o conceito de imagem ideal (Camargo, Justo, \& Jodelet, 2010). Em 2014, mais de 20 milhões de procedimentos estéticos cirúrgicos e não cirúrgicos foram realizados no mundo, sendo que as mulheres realizaram $86,3 \%$ destes procedimentos (International Society of Aesthetic Plastic Surgery [ISAPS], 2014). Para a mulher, o processo de envelhecimento pode acarretar maiores perdas, sentimentos de baixa-estima e alguns desequilíbrios psicológicos, na medida em que seus atributos físicos são fatores relevantes nas competições afetivas e profissionais, o que pode desencadear uma busca pelo rejuvenescimento (Teixeira et al., 2007).

Veiga (2012) aponta que as representações sociais sobre a velhice parecem estar diretamente associadas ao corpo e suas características durante o processo de envelhecimento. Considerando que as representações sociais orientam as práticas sociais, as práticas de rejuvenescimento parecem estar relacionadas também à compreensão de envelhecimento ativo, pois a juventude é associada à autonomia, à ênfase na atividade e na capacidade funcional dos indivíduos (Teixeira et al. 2007). Assim, este estudo tem como objetivo compreender as representações sociais do envelhecimento e do rejuvenescimento de mulheres jovens e de meia idade que adotam práticas de rejuvenescimento.

\section{Método}

\section{Delineamento}

Este estudo, de natureza qualitativa e quantitativa, possui um delineamento descritivo-comparativo, com corte transversal.

\section{Participantes}

As participantes da pesquisa foram acessadas a partir de indicações de pessoas do convívio social da primeira pesquisadora, por meio da técnica da "bola de neve" (snowball). A amostra foi composta por 40 mulheres, que possuíam entre 30 e 60 anos. Do total de 40 mulheres, 20 utilizaram procedimentos rejuvenescedores não invasivos nos últimos seis meses, sendo estes: cosméticos, exercícios físicos aeróbicos, massagem modeladora e dieta alimentar.
As outras 20 mulheres fizeram uso de procedimentos rejuvenescedores invasivos ou minimamente invasivos no mesmo período, tais como: injeção de toxina botulínica, cirurgias plásticas rejuvenescedoras, peelings químicos e bioplastia (preenchimento dérmico). A faixa etária foi estabelecida em função do período em que as marcas do envelhecimento tornam-se evidentes, a partir dos 30 anos (Papaléo Netto, 2002), sendo que optou-se por estender a faixa etária da amostra até os 60 anos, pois seria considerado o início da velhice no Brasil. As práticas de rejuvenescimento foram selecionadas a partir de critérios fornecidos por uma pesquisa encomendada pela Sociedade Brasileira de Cirurgia Plástica acerca de procedimentos cirúrgicos e não cirúrgicos frequentemente utilizados no Brasil (SBCP, 2015).

A média de idade foi de 42 anos ( $D P=10,46$ anos), sendo a idade mínima 30 anos e a idade máxima 60 anos. $\mathrm{O}$ grupo de mulheres que adota procedimentos não invasivos não fez em nenhum momento o uso de procedimentos invasivos (ou minimamente invasivos) concomitantemente. No entanto, todas as mulheres que adotam práticas de rejuvenescimento invasivas ou minimamente invasivas já adotaram ou ainda adotam concomitantemente práticas não invasivas de rejuvenescimento. A variável "tipo de prática de rejuvenescimento" foi agrupada em duas modalidades, conforme a Tabela 1.

\section{TABELA 1}

Distribuição das participantes segundo práticas de rejuvenescimento adotadas de acordo com a faixa etária

\begin{tabular}{|c|c|c|c|}
\hline \multirow{2}{*}{$\begin{array}{l}\text { Faixa } \\
\text { etária }\end{array}$} & \multicolumn{2}{|c|}{$\begin{array}{l}\text { Quantidade de mulheres que adotam } \\
\text { práticas de rejuvenescimento }\end{array}$} & \multirow{2}{*}{ Total } \\
\hline & $\begin{array}{l}\text { Práticas invasivas e } \\
\text { minimamente invasivas }\end{array}$ & $\begin{array}{l}\text { Apenas práticas } \\
\text { não invasivas }\end{array}$ & \\
\hline $30-39$ & 8 & 11 & 19 \\
\hline $40-49$ & 3 & 5 & 8 \\
\hline $50-60$ & 9 & 4 & 13 \\
\hline Total & 20 & 20 & 40 \\
\hline
\end{tabular}

No que se refere à escolaridade das participantes, a maior parte $(\mathrm{n}=21)$ frequentou até o ensino superior, sendo que 19 participantes concluíram o ensino médio. A renda familiar mensal média foi de 7,27 salários mínimos $(\mathrm{DP}=1,78)$, havendo predominância dessa média entre o grupo de mulheres que adotam práticas invasivas $(n=14)$. Foi verificado ainda que cinco pessoas eram aposentadas, duas donas de casa e as outras 33 desenvolviam atividades laborais remuneradas diversas. 


\section{Instrumentos}

Por meio das técnicas clássicas de intervenção para entrevista não-diretiva, foi proposto às participantes que estas respondessem de forma exaustiva a dois temas gerais: envelhecimento e rejuvenescimento. Assim, foi dito ao participante: "Peço para que você me conte tudo o que você acha importante e que pensa sobre o envelhecimento/rejuvenescimento". Foi utilizado um questionário com itens de caracterização das participantes, incluindo: idade, situação conjugal, situação profissional, renda familiar, além de questões fechadas acerca do comportamento passado das participantes em relação às práticas de rejuvenescimento (tipos de recursos utilizados e periodicidade de utilização de técnicas rejuvenescedoras). As entrevistas tiveram uma duração média de uma hora e 39 minutos (mínima 59 minutos e máxima duas horas e 15 minutos), sendo realizada por uma única pesquisadora, com o recurso de gravação de áudio.

\section{Procedimentos}

Em conformidade com a Resolução 466/2012 do Conselho Nacional de Saúde, a pesquisa foi submetida ao conselho de Comitê de Ética em Pesquisa com Seres Humanos (CEPSH) da Universidade Federal de Santa Catarina, com o número de aprovação 486.736. As participantes não foram identificadas em nenhum momento do estudo. Primeiramente, a pesquisadora entrou em contato por telefone com os indivíduos para fazer o convite da pesquisa. Diante da aceitação e preferência das participantes, a pesquisadora se deslocou para dependências isoladas das residências das participantes ou do local de trabalho, onde foram informadas sobre a pesquisa e sobre seus procedimentos, considerando a participação facultativa e a possibilidade de desistência ao longo do processo de pesquisa, sem implicação de ônus ou bônus.

As entrevistas semidiretivas foram analisadas por seus respectivos temas: 1) envelhecimento; 2) rejuvenescimento. Cada tema foi organizado em um corpus, que foi submetido a uma Classificação Hierárquica Descendente (CHD) simples, com o auxílio do programa informático IRAMUTEQ versão 0.6. Este software gratuito viabiliza diferentes tipos de análise de dados textuais, desde aquelas bem simples, como a lexicografia básica, cálculo de frequência de palavras, até análises multivariadas como classificação hierárquica descendente e análises de similitude (Camargo \& Justo, 2013). De acordo com Camargo e Justo (2013), a CHD visa obter classes de Segmentos de Texto (ST) que, ao mesmo tempo, apresentam vocabulário semelhante entre si e vocabulário diferente dos ST das outras classes. Já para as questões estruturadas, referentes aos dados sociodemográficos e de caracterização dos participantes, foi realizada estatística descritiva e relacional.

\section{Resultados}

\section{Representações sociais do envelhecimento}

O corpus "Envelhecimento" corresponde à parte da pesquisa que buscou investigar o que as participantes pensavam a respeito deste processo. Após a classificação hierárquica descendente (CHD) foram identificados 2.306 segmentos de textos sendo que 2.023 deles $(87,73 \%)$ foram considerados na análise. Eles foram compostos por 5.400 palavras que ocorreram 78.905, em média 14,61 vezes por palavra. A CHD dividiu o corpus em quatro classes sendo que em um primeiro momento houve a subdivisão em dois subcorpus, de um lado a classe quatro em oposição ao outro lado (classes um, dois e três). No segundo momento a classe três foi separada das classes um e dois; e por último, houve a separação entre as classes um e dois. A Figura 1 apresenta o nome das classes, o número de segmentos de texto (ST's) que as compõe, seguida de uma descrição de cada classe e das palavras de maior associação com a mesma, em função do duplo critério lexicográfico: ter frequência superior a frequência média por forma distinta e do coeficiente de associação qui-quadrado $\geq 15,36$ (quatro vezes maior que o valor mínimo).

As classes apresentadas no dendograma serão descritas primeiramente seguindo a ordem de partição e em seguida de proporção que representam em relação ao corpus total. A primeira classe a se diferenciar do restante do corpus (Classe quatro), denominada "Envelhecimento $\times$ estética", representa $14,98 \%$ dos ST's retidos na análise e apresenta predominantemente aspectos relacionados às mudanças na aparência decorrentes do envelhecimento, destacados principalmente por mulheres que adotam práticas invasivas e minimamente invasivas de rejuvenescimento. Os conteúdos que compõem esta classe abrangem as diferenças físicas apresentadas por homens e mulheres durante o processo de envelhecimento. Essas diferenças são apresentadas a partir da expressão "se olhar no espelho" e assim perceber alterações físicas. Nesse contexto, as rugas e os fios brancos surgem como preocupação das mulheres, enquanto o envelhecimento dos homens é destacado como esteticamente agradável às 


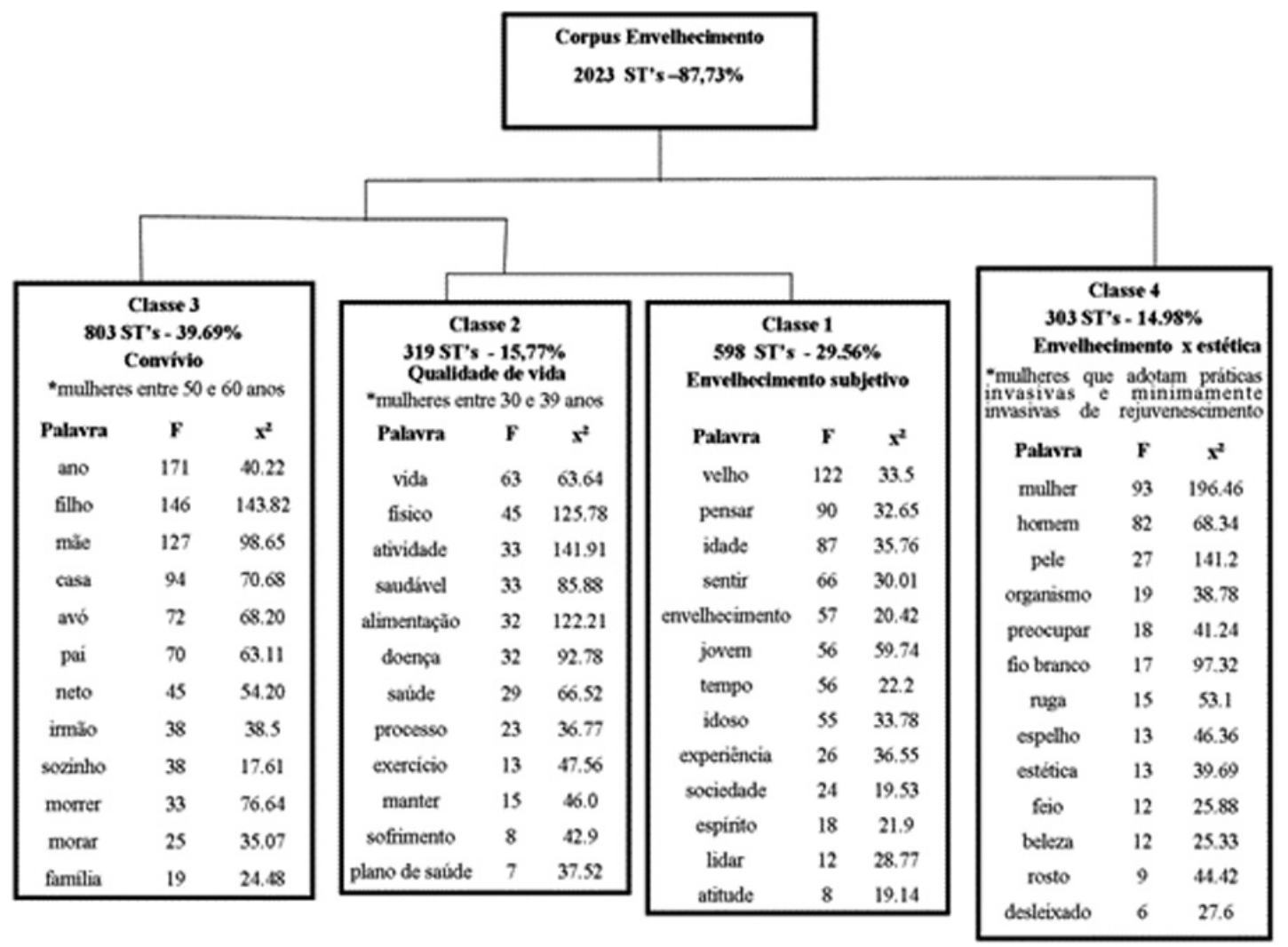

Figura 1. Dendograma da classificação hierárquica descendente do corpus "Envelhecimento".

mulheres. O extrato que segue ilustra essa questão: "Normalmente, o homem demonstra mais beleza no envelhecimento, não sempre, mas assim no geral, ele demonstra quando ele tem cabelos grisalhos, eles parecem mais bonitos e já a mulher quando aparece um fio de cabelo, meu deus estou ficando velha." (Participante usuária de práticas invasivas e minimamente invasivas de rejuvenescimento, 52 anos).

Há referência na classe quatro acerca da necessidade de cuidados com a aparência para a atenuação dos efeitos do envelhecimento no corpo. Efeitos como rugas e fios brancos são associados ao desleixo, como algo feio que pode ser embelezado. O rosto e a pele também surgem como objetos de preocupação, trazendo uma compreensão de que a beleza e o funcionamento orgânico estão em um constante e inevitável processo de desgaste.

Uma segunda partição diferencia do resto do material a classe "Convívio" (Classe três), que representa $39,69 \%$ do total dos ST's, correspondendo à maior classe gerada. A classe três traz conteúdos relacionados à situações de convívio atual e em projeção futura, com o passar dos anos, ao longo do processo de envelhecimento. O envelhecimento é retratado a partir da figura de idosos familiares, pai, mãe, avó, irmão. Nesse sentido, morar com a família surge como melhor alternativa na velhice em contraponto a morar e morrer sozinho. Há uma preocupação com a projeção futura da velhice em situações de convívio, a partir de um possível abandono dos filhos que saem de casa. O convívio com netos é destacado como desejado e o contato com parentes mais velhos é apontado como alternativa para que os filhos aprendam como lidar com os pais idosos no futuro. Dos segmentos de textos apresentados na classe "Convívio" (Classe três), 205 correspondem à mulheres com idades entre 50 e 60 anos. Deste modo, parece que as mulheres mais próximas da velhice, que adotam práticas de rejuvenescimento, apresentam maior preocupação em relação à situação de convívio em futura velhice, fazendo maior referência às experiências passadas com familiares idosos.

A classe um representa $29,56 \%$ dos ST's e recebeu o nome de "Envelhecimento subjetivo". Em oposição à classe quatro chamada "Envelhecimento $\times$ estética", a classe um aborda o envelhecimento menos sob o ponto de vista estético e mais sob a perspectiva da subjetividade, estando associada ao espírito jovem, ao modo de pensar e lidar com as adversidades, que pode fazer com que alguém seja jovem, independente da idade cronológica. Um trecho selecionado ilustra essa situação: "Nossa a cabeça dela é a mesma, os senti- 
mentos são os mesmos, o corpo é que não é. Então eu acho que quando a cabeça está legal tu não enxergas o corpo, nem a idade, tem que ter pensamento jovem." (Participante usuária de práticas invasivas e minimamente invasivas de rejuvenescimento, 40 anos). Nesta classe os conteúdos estão organizados principalmente em torno dos elementos: velho, pensar, idade e sentir. Nesse contexto, a passagem do tempo é citada como algo positivo, em decorrência do acúmulo de experiências de vida e a sociedade é destacada como meio social no qual o idoso é excluído ou se exclui, em função da idade.

A classe "Qualidade de vida" (classe dois) representa $15,77 \%$ dos ST's do corpus e foi produzida principalmente por mulheres com idade entre $30 \mathrm{e}$ 39 anos. Traz conteúdos que vinculam a qualidade de vida no envelhecimento ao estilo de vida das pessoas ao longo deste processo. A palavra "manter" nesta classe surge para destacar a necessidade de instaurar hábitos desde antes da velhice, mantendo-os durante o processo de envelhecimento. Nesse sentido, os elementos saúde e doença são destacados como dependentes da alimentação, atividade física e exercícios. O trecho que segue exemplifica esse contexto: "Não parar a vida, não estacionar por causa da idade, continuar a viver bem, viver de maneira saudável, se alimentar bem, fazer atividade física, passear, viajar, não ficar em casa cuidando de neto, ir para médico." (Participante usuária de práticas invasivas e minimamente invasivas de rejuvenescimento, 31 anos).

Analisando o dendograma do corpus é possível identificar o destaque para diferença na concepção de envelhecimento entre homens e mulheres. Mas também o envelhecimento é retratado a partir do relato de convívio com familiares, e como condição subjetiva independente da idade cronológica.

\section{Representações sociais do rejuvenescimento}

O corpus rejuvenescimento se refere ao conteúdo originado a partir do tema e buscava identificar o que as participantes pensavam a respeito deste tema. Para a análise o programa IRAMUTEQ reconheceu a separação do corpus em 40 textos, que foram fracionados em $2.415 \mathrm{ST}$ 's, dos quais $92,84 \%$ foram retidos na CHD. Os segmentos de texto foram compostos por 5.741 palavras que ocorreram 84.653 em média 14,74 vezes por palavra. A Figura 2 mostra as relações entre as classes resultantes da CHD.

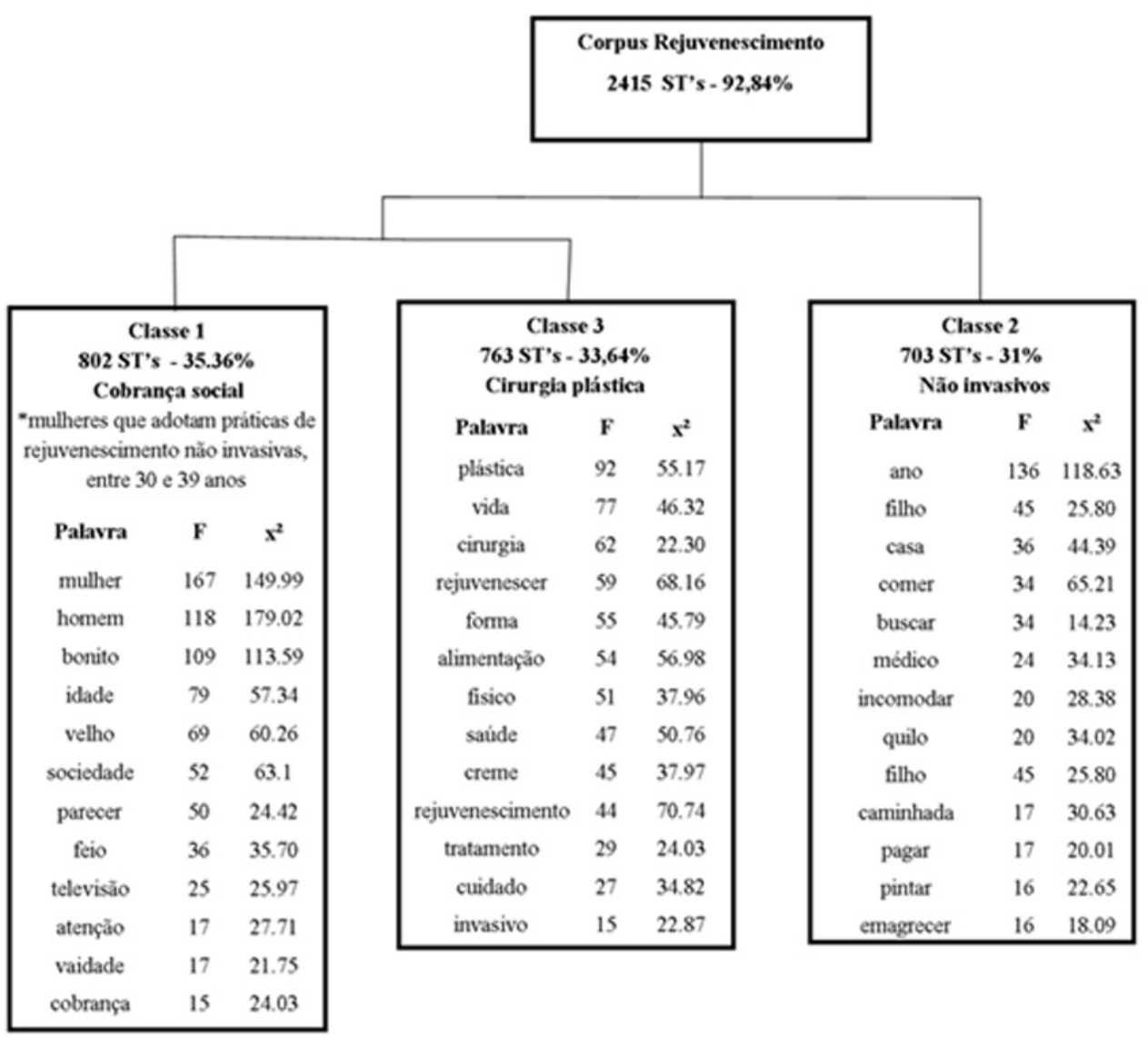

Figura 2. Dendograma da classificação hierárquica descendente do corpus "Rejuvenescimento". 
Em um primeiro momento, o programa dividiu o corpus em dois subcorpus, o primeiro originando a classe dois, em oposição ao que viria a ser as classes um e três. Num segundo momento, o segundo subcorpus sofreu outra partição, dividindo-se em outros dois subcorpus, o primeiro originando a classe um e o segundo a classe três.

A primeira classe a se diferenciar do restante do corpus (Classe dois), denominada "Não Invasivos" é composta por $31 \%$ dos ST's retidos na análise. Seus principais elementos são: ano, comer e casa. Os conteúdos que compõem esta classe tratam de recursos estéticos não invasivos que visam a busca da beleza e do rejuvenescimento físico. Nesta classe é apresentada a diferença entre o tempo para obtenção de resultados quando se utiliza práticas não invasivas, em comparação a práticas invasivas, sendo essa contagem de tempo realizada a partir do elemento ano. Nesta classe, os filhos associados ao processo de gravidez e parto são apresentados como variáveis que aceleram os efeitos do envelhecimento, a partir do ganho de peso, destacado a partir dos elementos quilo e emagrecer. Como práticas de rejuvenescimento não invasivas são salientadas na classe dois: pintar os cabelos brancos e realizar caminhadas com o objetivo de emagrecer.

Ainda na classe dois o médico é citado como o profissional que pode indicar práticas de rejuvenescimento invasivas ou não invasivas. Nesse contexto, o elemento incomodar está vinculado aos aspectos do envelhecimento que fazem com que as mulheres procurem um médico e/ou realizem práticas de rejuvenescimento em casa. Nessa classe, comer de forma equilibrada é evidenciado como prática doméstica de rejuvenescimento adotada pelas participantes. Tais questões podem ser exemplificadas a partir do trecho: "Já é mais difícil com 34 anos perder peso, assim que faço em casa, eu cuido para comer direito, mas às vezes como coisas que podem atrapalhar." (Participante usuária de práticas não invasivas de rejuvenescimento, 34 anos).

A classe "Cirurgia Plástica" (Classe três) é composta por $33,64 \%$ do total dos ST's e está associada predominantemente às críticas acerca das práticas invasivas de rejuvenescimento. A cirurgia plástica é retratada como uma prática fácil e rápida que deforma e está associada aos exageros e à falta de limites. O seguimento de texto exemplifica esse contexto: "Se eu penso em rejuvenescimento me vem na cabeça a imagem da mulher que certamente exagerou, que exagerou no botox, plástica, que está em uma tentativa muito desesperada de rejuvenescer, de uma forma que ela não teve sucesso." (Participante usuária de práticas não invasivas de rejuvenescimento, 31 anos).
Essa compreensão da cirurgia plástica é presente também quando as participantes apresentam seus entendimentos acerca de rejuvenescer e rejuvenescimento. O rejuvenescimento é apresentado como um recurso desesperado, originado por influências comerciais, que quando realizado em exagero modifica a vida das pessoas, conforme extrato: "Então a pessoa quer mudar, acho que está se escravizando. É um interesse comercial, marketing, as propagandas estão aí, não estão preocupados que a pessoa vai usar ou deixar de usar." (Participante usuária de práticas invasivas e minimamente invasivas de rejuvenescimento, 51 anos).

Os elementos saúde e alimentação, presentes nesta classe "Cirurgia plástica", são apontados como alternativas diante da cirurgia plástica, pois esta é vinculada a não aceitação das rugas, enquanto o cuidado com a alimentação é associado à saúde. Desse modo, o rejuvenescimento relacionado à saúde é destacado como algo positivo e em oposição à cirurgia plástica.

$\mathrm{Na}$ classe três também é evidenciado que as mulheres se preocupam com cuidados corporais para manutenção da beleza física. Cuidados corporais a partir da utilização de cremes parecem ser socialmente aceitos por serem considerados mais naturais quando comparados às cirurgias plásticas, que podem transformar traços físicos naturais. Assim, os métodos invasivos são indicados como os mais imediatos no que se refere a resultados, porém mais perigosos, pois podem resultar em uma transformação artificial da aparência, conforme o trecho: "Eu acho isso meio perigoso, eu tenho medo do resultado final, eu acho que quem procura métodos invasivos talvez tenha uma ansiedade de imediatismo." (Participante usuária de práticas não invasivas de rejuvenescimento, 31 anos). Desse modo, é apontada a necessidade de cuidado ao utilizar práticas de rejuvenescimento, tendo em vista que as cirurgias plásticas podem tornar a pessoa feia e, portanto, não ter o desfecho de embelezamento e rejuvenescimento esperado.

A classe "Cobrança social" (classe um) representa $35,36 \%$ dos ST's retidos na análise e apresenta majoritariamente ST's pertencentes às mulheres que adotam práticas de rejuvenescimento não invasivas, com idade entre 30 e 39 anos. A classe um corresponde a maior classe e traz conteúdos que vinculam o rejuvenescimento à cobrança social acerca da manutenção da aparência jovem. Nesse contexto, os elementos homem e mulher indicam a diferença entre a aceitação social do envelhecimento físico destes, em que o envelhecimento do homem é menos destacado e até considerado positivamente. A mulher é apontada como aquela que repara e cobra as práticas de 
rejuvenescimento e de beleza das outras mulheres. $\mathrm{O}$ trecho que segue exemplifica o exposto: "A sociedade é mais cruel com o envelhecimento da mulher do que do homem, acho que a pressão social é difícil, através da midia, das outras mulheres, dessa coisa que eu disse, que mulher é velha e homem fica charmoso." (Participante usuária de práticas não invasivas de rejuvenescimento, 31 anos).

Associados ao elemento idade há trechos que enfatizam a diferença que deve existir no modo de se comportar e de se vestir ao longo do processo de envelhecimento. Nesse contexto, o envelhecimento é considerado algo natural, algo bonito, que não deve ser tratado ou evitado, mas sim aceito como uma nova etapa do desenvolvimento, conforme extrato destacado: "Envelhecer é bonito, eu acho lindo o envelhecimento, eu acho uma coisa assim que é natural, como você ver uma criança virar um adolescente, virar um adulto, é bonito, todo mundo acha bonito. Por que virar um velho fica feio?" (Participante usuária de práticas não invasivas de rejuvenescimento, 31 anos).

A sociedade é destacada na classe "Cobrança social" como instância que institui e estimula a cobrança por uma aparência rejuvenescida. As mulheres são apontadas como mais vaidosas por procurarem se adequar às cobranças sociais ao adotarem práticas de rejuvenescimento para "chamar a atenção". Assim, a sociedade é responsabilizada pela procura excessiva por práticas de rejuvenescimento, enquanto a televisão, a partir da figura de artistas com a aparência jovem é apontada como instrumento de influência dos telespectadores, que buscarão modificar a própria aparência para melhorar aspectos de suas vidas.

$\mathrm{O}$ contexto que envolve o rejuvenescimento envolve a diferença entre o tempo para obtenção de resultados quando se utiliza práticas não invasivas, em comparação à práticas invasivas e minimamente invasivas. Há certa predominância de críticas acerca das práticas invasivas de rejuvenescimento, principalmente cirurgias plásticas. A adoção de práticas de rejuvenescimento é apontada como resultado da cobrança social e nesse sentido a própria mulher é apresentada como responsável pela cobrança de suas semelhantes.

\section{Discussão}

O processo do envelhecimento pode ser significado de formas distintas, de acordo com os períodos históricos, com os contextos sociais e culturais em que as representações emergem. A partir das entrevistas que constituíram o corpus "Envelhecimento" é possível verificar que as mulheres com idade entre 30 e 39 anos enfatizam que para "se manter" e favorecer a saúde, o indivíduo deve conservar bons hábitos alimentares, praticar atividades físicas e adotar a medicina preventiva. Tais dados parecem convergir com os resultados da avaliação multidimensional dos determinantes do envelhecimento ativo em idosos de um município de Santa Catarina (Vicente \& Santos, 2013). Nesse sentido, a prevalência de saúde ou doença durante o envelhecimento dependeria dos hábitos adotados desde antes da velhice. Tendo em vista que o declínio do sistema orgânico tem seu início a partir dos 30 anos de idade (Papaléo Netto, 2002) é possível considerar que as participantes entre 30 e 39 anos parecem apresentar maior preocupação com aspectos preventivos do envelhecimento, relacionando suas representações do envelhecimento às práticas de saúde que podem retardar este processo.

A representação do envelhecimento vinculada ao desgaste físico, apresentada pelas mulheres que adotam práticas de rejuvenescimento não invasivas, parece se contrapor à representação do envelhecimento associada às transformações estéticas. Esta é apresentada majoritariamente por mulheres que utilizam recursos estéticos invasivos para rejuvenescer. Essas mulheres adotam um número maior de práticas de rejuvenescimento quando comparadas àquelas que utilizam apenas práticas não invasivas. Assim é possível identificar, conforme Rouquette (1998), que as representações sociais são condições de práticas e, ao mesmo tempo, as práticas promovem transformações de representações.

A partir dos conteúdos obtidos das análises do corpus "Envelhecimento", verifica-se que principalmente entre as mulheres que adotam práticas invasivas e minimamente invasivas de rejuvenescimento, as ideias associadas ao envelhecimento apresentam aspectos relacionados às mudanças na aparência, a partir da ênfase nas diferenças físicas entre homens e mulheres durante este processo. Assim, as rugas e os fios brancos são destacados como preocupações exclusivas das mulheres, pois os homens são considerados "charmosos" quando os sinais do envelhecimento se manifestam fisicamente.

Para ambos os grupos de mulheres, os cuidados com a aparência para atenuação dos efeitos do envelhecimento é enfatizado a partir da diferença entre belo e feio, em que o jovem é considerado belo enquanto o envelhecimento é caracterizado como feio. Nesse contexto, rugas e fios brancos são associados à feiúra e ao desleixo. No estudo etnográfico desenvolvido por Veiga (2012), a fim de identificar as representações sociais do envelhecimento feminino, o corpo em 
envelhecimento aparece como um corpo em declínio, associado à feiúra, em contraponto à juventude, que é apresentada como sinônimo de beleza. Assim, as práticas de rejuvenescimento ganham ênfase com os recursos para embelezamento, sustentando a ideia de que o envelhecimento é caracterizado por feiúra e a juventude relacionada à beleza (Craciun \& Flick, 2014).

Nas entrevistas presentes no corpus "Envelhecimento" a idade é citada como fator de exclusão social pelo qual a sociedade ou o próprio idoso é excluído ou se exclui. Estes dados já haviam sido igualmente reportados por Santos, Tura e Arruda (2013), em que a velhice é representada como sinônimo de envelhecimento, marcada pela solidão, abandono e exclusão, expressando diretamente uma segregação do idoso, seja das relações familiares, laços de amizade ou de outros círculos sociais.

Com a CHD do corpus "Envelhecimento" é possível identificar que entre ambos os grupos de mulheres o envelhecimento é objetificado na figura do idoso, sendo personificado em familiares que alcançaram a velhice. As mulheres mais próximas da velhice apresentam maior preocupação em relação à situação de convívio em futura velhice. O convívio com os netos é apresentado como algo desejado, enquanto o abandono dos filhos que saem de casa é destacado como algo indesejado. Nesse contexto, para ambos os grupos, o contato com a família é considerado um aspecto importante no enfrentamento da velhice, principalmente para mulheres mais velhas, que estão próximas desta etapa e temem a saída dos filhos e o rompimento dos laços familiares (Oliveira et al., 2012).

$\mathrm{O}$ estilo de vida é apontado no corpus "Envelhecimento" como fator de influência para o envelhecimento com qualidade de vida, sendo destacados como importantes a alimentação, a atividade física e os exercícios. Nesse sentido, para ambos os grupos de mulheres, as representações sociais do envelhecimento e do rejuvenescimento parecem associadas à saúde, sendo que as práticas de saúde que influenciam no estilo de vida durante o envelhecimento podem proporcionar o rejuvenescimento. Aspecto semelhante é evidenciado por Teixeira et al. (2007), pois em sua pesquisa, o termo rejuvenescimento foi associado à caminhada e aos exercícios físicos. Nesse sentido, o retardo do envelhecimento é aceito como sinônimo de rejuvenescimento, sendo este relacionado à saúde e em decorrência disso, destacado como algo positivo em oposição à cirurgia plástica.

Há a menção nas entrevistas dos cuidados corporais a partir da utilização de cremes, que são considerados mais naturais por não ocasionarem a transformação brusca de traços físicos e apresentarem menos riscos à saúde, quando comparados à cirurgia plástica. A pesquisa desenvolvida por Silva e Penalva (2014) aponta que os aspectos negativos do rejuvenescimento fazem referência à aparência artificial promovida por estas práticas. Assim, o rejuvenescimento é desejado, porém a adoção de práticas não invasivas parece motivada pelo receio em relação a uma aparência artificial, associada ao exagero das práticas invasivas e minimamente invasivas.

As representações sociais envolvem a pertença social dos indivíduos com as implicações afetivas e normativas, com as interiorizações de experiências, práticas, modelos de condutas e pensamento (Jodelet, 2001). Tendo em vista que as principais críticas em relação à cirurgia plástica são realizadas por mulheres entre 30 e 39 anos, é possível que a intensidade na adoção de práticas de rejuvenescimento seja alterada ao longo do processo de envelhecimento, fazendo com que as mulheres que inicialmente adotavam práticas não invasivas passem a considerar a necessidade de adoção de práticas invasivas e minimamente invasivas.

No corpus "Rejuvenescimento", principalmente entre as mulheres que adotam práticas não invasivas, o envelhecimento é considerado algo natural e inevitável, que deve ser aceito como uma nova etapa do desenvolvimento, associado às práticas de rejuvenescimento não invasivas, principalmente voltadas à saúde. De modo similar, no corpus "envelhecimento" as mulheres que adotam práticas invasivas e minimamente invasivas enfatizam a prática de atividades físicas como relevante para o envelhecimento saudável, o que sugere que este seja um dos elementos conectores entre tais representações. É importante mencionar que as práticas de rejuvenescimento associadas à saúde não se encontram em oposição às normas sociais vigentes, enquanto as práticas estéticas invasivas, cuja representação aparece associada ao exagero e riscos à saúde, podem ser alvos de contestação social, sugerindo a influência da desejabilidade social nas respostas.

Algumas participantes que adotam práticas de rejuvenescimento não invasivas apontam nas entrevistas a diferença que deve existir no modo de se comportar e de se vestir em cada fase do desenvolvimento, com destaque para a velhice como uma etapa diferente da juventude. Sobre vestimentas e modo de se comportar na velhice, Wottrich (2012) aponta que o corpo é um elemento relevante na caracterização da velhice e, nesse contexto, "ser velho" está associado ao modo de se vestir, rugas aparentes, viço, motivação para as tarefas cotidianas e manutenção da saúde. 
A partir dos resultados obtidos é possível afirmar que principalmente as mulheres que adotam práticas de rejuvenescimento não invasivas, com idade entre 30 e 39 anos, vinculam o rejuvenescimento por métodos invasivos e minimamente invasivos à cobrança social, sendo a mulher marcada como principal agente de cobrança em relação ao aspecto rejuvenescido das outras mulheres. A diferença na aceitação social do envelhecimento do homem e da mulher, com favorabilidade ao homem é igualmente destacada no corpus "Envelhecimento". Nesse sentido, Debert (2011) afirma que a procura das mulheres por produtos e recursos que combatam os sinais do envelhecimento é desigual em relação aos homens, pois socialmente as rugas e os cabelos brancos são associados ao amadurecimento e charme no caso dos homens e descuido no caso das mulheres. Assim, estas mulheres destacam a cobrança social associada ao rejuvenescimento, sendo que o mesmo não ocorre com as mulheres mais velhas. Tal fato se justificaria, pois de acordo com Camargo, Goetz, Bousfield e Justo (2011) conforme aumenta a faixa etária, as mulheres diminuem o monitoramento do seu corpo em relação às normas sociais.

Principalmente as mulheres que adotam práticas de rejuvenescimento não invasivas apontam que em apelos comerciais e na televisão, a partir da figura de artistas com a aparência jovem, as pessoas são influenciadas a modificarem a própria aparência, buscando com isso melhorar aspectos de suas vidas. A mídia, por ser uma importante fonte de difusão de representações sociais, desempenha um papel significativo no processo de valorização da juventude em detrimento da velhice (Couto \& Meyer, 2012). Conforme já destacado por Castro et al, (2016), a mídia, propaga representações sociais que são utilizadas como meio para persuadir e associar a aparência jovem como essencial e fundamental para a realização pessoal, a felicidade e a valorização social, contribuindo para a formação de representações sociais que possivelmente possam orientar e/ou justificar a busca por estratégias para combater o processo de envelhecimento.

A partir da discussão dos resultados é possível identificar elementos que apontam para uma representação social do rejuvenescimento vinculada às práticas de saúde, enquanto que as representações sociais do envelhecimento associam-se às trans- formações corporais. No entanto, para ambos os objetos, os aspectos subjetivos relacionados ao "sentir-se jovem" parecem elementos relevantes para organização representacional.

\section{Considerações Finais}

A representação social do envelhecimento apresenta aspectos comuns entre as participantes, e aspectos específicos, de acordo com a faixa etária e com o tipo de prática adotada: não invasivas ou invasivas e minimamente invasivas. Assim, como elemento representacional comum aos grupos, é possível indicar o envelhecimento subjetivo, relacionado ao "sentirse velho" ou "sentir-se jovem" e condicionado aos aspectos emocionais e escolhas subjetivas realizadas pelo indivíduo que envelhece.

Ao mesmo tempo em que o envelhecimento é destacado em função de uma condição subjetiva, as mulheres parecem adotar práticas de rejuvenescimento de cunho funcional e estético, justificadas sob o ponto de vista da manutenção da saúde. Ao mesmo tempo em que se apresentam inúmeros modos de cuidar da beleza do corpo e rejuvenescer, vive-se um momento de constantes campanhas pela saúde, visando cuidados com a manutenção das funcionalidades do corpo.

A relação do bem-estar subjetivo e da saúde como importantes elementos na representação do rejuvenescimento e do envelhecimento parece apontar para a pertinência de implementação de espaços sociais que propiciem a educação em saúde e que potencializem a realização de práticas de rejuvenescimento funcionais, por meio da promoção de ambientes para a realização de atividades físicas e para discussão social, visando a implantação de hábitos alimentares adequados, que possam retardar aspectos do envelhecimento. Assim, considerando que elementos das representações sociais do rejuvenescimento e do envelhecimento podem ser ocultados em contextos diferentes, parece relevante apontar a necessidade de novos estudos que objetivem verificar as representações sociais sobre o envelhecimento e sobre o rejuvenescimento emergentes em função do contexto de inserção, pois diferentes elementos da representação poderiam ser ativados diante de contextos de saúde ou de beleza. 


\section{Referências}

Baltes, P. B. (1987). Theorical propositions of lifespan developmental psychology on the dynamics between growth and decline. Developmental Psychology, 23(5), 611-626. http://dx.doi.org/10.1037/0012-1649.23.5.611

Baltes, P. B. \& Baltes, M. M. (1990). Psychological perspectives on successful aging: the model of selective optimization with compensation. In P. B. Baltes \& M. M. Baltes (Ed.), Sucessful aging: perspectives from the behavioral sciences (pp. 1-34). Cambridge: Cambridge University Press. http://dx.doi.org/10.1017/CBO9780511665684

Camargo, B. V., Justo, A. M., \& Jodelet, D. (2010). Normas, representações sociais e práticas corporais. Interamerican Journal of Psychology, 44(3), 449-457.

Camargo, B. V., Goetz, E. R., Bousfield, A. B., \& Justo, A. M. (2011). Representações sociais do corpo: estética e saúde. Temas em Psicologia, 19(1), 257-268.

Camargo, B. V. \& Justo, A. M. (2013). IRAMUTEQ: um software gratuito para análise de dados textuais. Temas em Psicologia, 21(2), 513-518. http://dx.doi.org/10.9788/TP2013.2-16

Camargo, B.V., Contarello, A., Wachelke, J. F. R., Morais, D.X., \& Piccolo, C. (2014). Representações sociais do envelhecimento entre diferentes gerações no Brasil e na Itália. Psicologia em Pesquisa, 8(2), 179-188.

Castro, A., Aguiar, A. D., Berri, B., \& Camargo, B. V. (2016). Representações sociais do rejuvenescimento na mídia impressa. Temas em Psicologia, 24(1), 117-130. http://dx.doi.org/10.9788/TP2016.1-08

Couto, E. \& Meyer, D. (2012). Viver para ser velho? Cuidado de si, envelhecimento e juvenilização. Revista Entreideias: Educação, Cultura e Sociedade, 19, 21-32. Recuperado de: http://www.portalseer.ufba.br/index.php/entreideias/ article/view/5518/4297

Craciun, C., \& Flick, U. (2014). I will never be the granny with rosy cheeks: Perceptions of aging in precarious and financially secure middle-aged Germans. Journal of aging studies, 29, 78-87. http://dx.doi.org/10.1016/j. jaging.2014.01.003

Debert, G. G. (2011). A velhice e tecnologias do rejuvenescimento. In M. Goldenberg (Org.), Corpo, envelhecimento e felicidade (pp. 65-80). Rio de Janeiro: Civilização Brasileira.

Fundo de População das Nações Unidas (UNFPA). (2011). Relatório sobre a situação da população mundial 2011. Recuperado em 12/06/2016, de: http:/www.unfpa.org.br/novo/index.php?option=com_content\&view=article\&id=795

Instituto Brasileiro de Geografia e Estatística (IBGE). (2015). Pesquisa Nacional por Amostra de Domicílios: síntese de indicadores 2014. Recuperado em 12/06/2016, de: http://biblioteca.ibge.gov.br/visualizacao/livros/liv94935.pdf

International Society of Aesthetic Plastic Surgery [ISAPS], (2014). ISAPS International Survey on Aesthetic/Cosmetic: Procedures Performed in 2014. Recuperado em 20/06/2016, de: http://www.isaps.org/Media/Default/globalstatistics/2015\%20ISAPS\%20Results.pdf

Jodelet, D. (1989). Les representationes sociales. Paris: Press Universitaires de France.

Jodelet, D. (2001) Representações sociais: um domínio em expansão. In D. Jodelet (Org.), As representações sociais (pp. 17-41). Rio de Janeiro: EDUERJ.

Moscovici, S. (1961/2012). A psicanálise, sua imagem e seu público. Petrópolis: Vozes.

Neri, A. L. (2013) Conceitos e teorias sobre o envelhecimento. In L. Malloy-Diniz et al. (Eds.), Neuropsicologia do envelhecimento: uma Abordagem Multidimensional (pp. 17-42). Porto Alegre: Artmed.

Oliveira, A. M. M. et al. (2012). Representações sociais e envelhecimento: uma revisão integrativa de literatura. Rev. bras. ciênc. saúde, 16(3). http://dx.doi.org/10.4034/RBCS.2012.16.03.21

Silva, M. C., Ogata, M. N., \& Oliveira, D. C. (2015). O estado de arte das produções científicas nacionais das representações sociais do envelhecimento na perspectiva da saúde. Kairós Gerontologia, 18(19), 49-63. Recuperado em 12/06/2016, de: http://revistas.pucsp.br/index.php/kairos/article/view/27243/19290

Silva, P. C. \& Penalva, G. A. (2014). Nem todas querem ser Madonna: representações sociais da mulher carioca, de 50 anos ou mais. Estudos Feministas, 173-193. Recuperado em 12/06/2016, de: http://www.scielo.br/pdf/ref/v22n1/ 10.pdf

Papaléo Netto, M. (2002). Gerontologia: a velhice e o envelhecimento em visão globalizada. São Paulo: Atheneu.

Rouquette. M. L. (1998). Representações e práticas sociais. In A. S. P. Moreira \& D. C. de Oliveira (Orgs.), Estudos interdisciplinares de representação social (pp. 39-46). Goiânia: AB.

Santos, V. B., Tura, L. F. R., \& Arruda, A.M.S. (2013). As representações sociais de "pessoa velha" construídas por idosos. Saúde e sociedade, 22(1), 138-147. http://dx.doi.org/10.1590/S0104-12902013000100013

Sociedade Brasileira de Cirurgia Plástica [SBCP] (2015). Análise Comparativa das Pesquisas 2009 e 2015: Situação da Cirurgia Plástica no Brasil. Recuperado em 12/06/2016, de: http://www2.cirurgiaplastica.org.br/restrito/wp-content/ uploads/2016/06/pesquisa-SBCP-2009-14.pdf

Teixeira, M. C. T. V., Settembre, F. M., \& Leal, S. B. (2007). A survey of women's social representations of aging and rejuvenation. The Spanish Journal of Psychology, 10(1), 104-114. http://dx.doi.org/10.1017/S1138741600006363

Torres, T.L., Camargo, B. V., Boulsfield, A. B., \& Silva, A. O. (2015). Representações sociais e crenças normativas sobre envelhecimento. Ciência \& Saúde Coletiva, 20(12), 3621-3630. http://dx.doi.org/10.1590/1413812320152012.01042015 
Veiga, M. R. M. (2012). Mulheres na meia-idade: corpos, envelhecimentos e feminilidades. (Dissertação de Mestrado). Universidade Federal de Santa Maria, Santa Maria, RS.

Vicente, F. R. \& Santos, S. M. A. D. (2013). Avaliação multidimensional dos determinantes do envelhecimento ativo em idosos de um município de Santa Catarina. Texto \& Contexto Enfermagem, 22(2), 370-8. http://dx.doi.org/10.1590/ S0104-07072013000200013

Veloz, M. C. T., Nascimento-Schulze, C. M., \& Camargo, B. V. (1999). Representações sociais do envelhecimento. Psicologia: Reflexão e Crítica, 12(2), 479-501. http://dx.doi.org/10.1590/S0102-79721999000200015

Wachelke, J. \& Contarello, A. (2011). Italian students' social representation on aging: an exploratory study of a representational system. Psicologia Reflexão e Crítica, 24(3), 551-560. http://dx.doi.org/10.1590/S010279722011000300016

Wottrich, L. H. (2012). O que a telenovela diz sobre a velhice? Representações da beleza e do cuidado de si em Passione. Cadernos de Comunicação, 15(1). 102-113. http://dx.doi.org/10.5902/2316882X

Zani, R. (1994). Beleza e rejuvenescimento: métodos e técnicas. São Paulo: Saraiva.

\begin{abstract}
Autores:
Amanda Castro - Mestra, Universidade Federal de Santa Catarina - UFSC.

Larissa Antunes - Mestra, Universidade Federal de Santa Catarina - UFSC.

Annie Mehes Maldonado Brito - Doutora, Universidade Federal do Pampa - UNIPAMPA.

Brigido Vizeu Camargo - Doutor, Universidade Federal de Santa Catarina - UFSC.
\end{abstract}

\title{
Endereço para correspondência:
}

Amanda Castro

Servidão Pedro Manoel da Silveira, 280B

88049-520 Florianópolis, SC, Brasil

<amandacastrops@gmail.com>

Recebido em: 20.11.2015

Aceito em: 06.07.2016 